\title{
BMJ Open Cohort profile: the Biology, Affect, Stress, Imaging and Cognition (BASIC) study on perinatal depression in a population-based Swedish cohort
}

Cathrine Axfors (D) , ${ }^{1}$ Emma Bränn (D) , ${ }^{1}$ Hanna E Henriksson, ${ }^{1}$ Charlotte Hellgren, ${ }^{1}$ Theodora Kunovac Kallak, ${ }^{1,2}$ Emma Fransson (D) ,1,3 Susanne Lager (1) ,,2 Stavros I Iliadis, ${ }^{1}$ Sara Sylvén, ${ }^{1,4}$ Fotios C Papadopoulos, ${ }^{4}$ Lisa Ekselius, ${ }^{4}$ Inger Sundström-Poromaa, ${ }^{1}$ Alkistis Skalkidou (i) ${ }^{1}$

To cite: Axfors C, Bränn E, Henriksson HE, et al. Cohort profile: the Biology, Affect, Stress, Imaging and Cognition (BASIC) study on perinatal depression in a population-based Swedish cohort. BMJ Open 2019;9:e031514. doi:10.1136/ bmjopen-2019-031514

- Prepublication history and additional material for this paper are available online. To view these files, please visit the journal online (http://dx.doi org/10.1136/bmjopen-2019031514).

Received 07 May 2019 Revised 12 September 2019 Accepted 18 September 2019

\section{Check for updates}

(c) Author(s) (or their employer(s)) 2019. Re-use permitted under CC BY-NC. No commercial re-use. See rights and permissions. Published by BMJ.

${ }^{1}$ Women's and Children's Health, Uppsala University, Uppsala,

Sweden

${ }^{2}$ Centre for Reproductive Biology in Uppsala (CRU), Uppsala University, Uppsala, Sweden ${ }^{3}$ Department of Microbiology, Tumor and Cell Biology, Karolinska Institute, Stockholm, Sweden

${ }^{4}$ Department of Neuroscience, Psychiatry, Uppsala University, Uppsala, Sweden

Correspondence to

Professor Alkistis Skalkidou;

Alkistis.Skalkidou@kbh.uu.se

\section{ABSTRACT}

Purpose With the population-based, prospective Biology, Affect, Stress, Imaging and Cognition (BASIC) cohort, we aim to investigate the biopsychosocial aetiological processes involved in perinatal depression (PND) and to pinpoint its predictors in order to improve early detection. Participants From September 2009 to November 2018, the BASIC study at Uppsala University Hospital, Sweden, has enrolled 5492 women, in 6478 pregnancies, of which $46.3 \%$ first-time pregnancies and with an average age of 31.5 years. After inclusion around gestational week 16-18, participants are followed-up with data collection points around gestational week 32 , at childbirth, as well as three times postpartum: after 6 weeks, 6 months and 1 year. At the last follow-up, $70.8 \%$ still remain in the cohort.

Findings to date In addition to internet-based surveys with self-report instruments, participants contribute with biological samples, for example, blood samples (maternal and from umbilical cord), biopsies (umbilical cord and placenta) and microbiota samples. A nested case-control subsample also takes part in cognitive and emotional tests, heart rate variability tests and bioimpedance tests. Subprojects have identified various correlates of PND of psychological and obstetric origin in addition to factors of the hypothalamic-pituitary-adrenal axis and immune system.

Future plans In parallel with the completion of data collection (final follow-up November 2019), BASIC study data are currently analysed in multiple subprojects. Since 2012, we are conducting an ongoing follow-up study on the participants and their children up to 6 years of age (U-BIRTH). Researchers interested in collaboration may contact Professor Alkistis Skalkidou (corresponding author) with their request to be considered by the BASIC study steering committee.

\section{INTRODUCTION}

Perinatal depression (PND) affects around $12 \%$ of pregnant women and new mothers worldwide $^{1}$ and constitutes a veritable challenge for public health. Being at least as common as depression in other periods in

\section{Strengths and limitations of this study}

- Population-based, prospective cohort study of 6478 pregnancies.

- Various biological and psychological measures at multiple follow-up points.

- Perinatal depression assessment with the well-established self-report instrument Edinburgh Postnatal Depression Scale.

- Low consent rate (20.4\%) and over-representation of women born in Scandinavia, with high education, who are cohabiting with the child's father.

- Relatively low attrition $(70.8 \%$ remaining at 12-month follow-up), but greater dropout in women with baseline depressive symptoms.

life, ${ }^{2}$ PND manifests itself at a time of considerable social responsibility. Depression may impede a sensitive interaction with one's child and the adherence to caregiving recommendations. ${ }^{34}$ In the wake of such difficulties lies the risk of impaired infant development, ${ }^{5}$ especially since perinatal-onset depression may follow a chronic or recurrent course over years to follow. ${ }^{6}$ Yet, PND, even at its most severe forms, is too often undiagnosed and untreated. According to a Swedish register study, one in four women who commit suicide in the perinatal period have no established contact with psychiatry. ${ }^{7}$ Furthermore, whereas suicide rates in the general population have decreased over the past decades, maternal suicide rates showed no such improvement. ${ }^{7}$

Even though multiple risk factors for PND have been identified, especially in recent years, there is still a shortage of longitudinal, large-scale investigations. ${ }^{2}$ Among psychological and social risk factors, moderate to strong such are, for example, previous mental 
morbidity, life stress, trauma and low socioeconomic status. ${ }^{2}$ Furthermore, the pronounced physiological changes inherent to the perinatal period have spurred hypotheses of a distinguishable biological pattern. ${ }^{2}$ Integrative research, exploring the interplay of these biopsychosocial factors, is particularly warranted. ${ }^{8}$

In this context, the Biology, Affect, Stress, Imaging and Cognition (BASIC) study in Uppsala, Sweden, was initiated in 2009 and is still ongoing. The purpose of the BASIC study is to enrich and expand our knowledge on the pathophysiological processes underlying PND and also to pinpoint both epidemiological and biological predictors of the disease in order to improve early detection.

\section{Cohort description}

BASIC is a population-based, prospective cohort study at the Department of Obstetrics and Gynaecology at Uppsala University Hospital. In the county of Uppsala, all pregnant women are referred to Uppsala University Hospital for a routine ultrasound examination at gestational week 16-18, and $97 \%$ of women choose to attend. Around 4200 women give birth at Uppsala University Hospital per year. Women listed for routine ultrasound examination are invited to the BASIC study. Exclusion criteria are age below 18 years, insufficient ability to read and understand Swedish, protected identity, known bloodborne infections and/or non-viable pregnancy as diagnosed by routine ultrasound.

Invited women receive written information about the BASIC study by post, together with the telephone number and email address to the study personnel. All participants give their written consent, separately for every modality they wish to take part in (e.g., questionnaires, surveys, blood samples, tissue samples and microbiota samples). Those selected for the nested case-control group receive additional information around gestational week 37 and a separate consent form regarding test sessions (see Data collection section). A parallel track of recruitment involves women giving birth via elective caesarean section (CS). Since 2013, women attending their preoperative appointment for elective CS are invited to the study and take part from childbirth and onwards. Analogously to the main track of recruitment, women in the elective CS group give their written consent to each preferred modality of study measurement after receiving written information. Participants may choose to decline specific measurements and to change their consent at any time as well as retrospectively.

Between September 2009 and November 2018, women during 31687 pregnancies have been invited to the study. In 6478 of these pregnancies, the women chose to participate (consent rate 20.4\%). So far, the total number of participants is 5492, with some participating in the study two $(n=842)$ or three $(n=72)$ times. Compared with the overall population of pregnant women in Uppsala and Sweden, participants are to a higher extent born in Scandinavia, living with the child's father, have a longer education and are less often overweight or obese. Moreover, they are on average slightly older, more often primiparous and their newborns are less often born prematurely or with low birth weight (table 1).

Participants are followed-up at multiple points from baseline at gestational week 16-18 through 1-year postpartum (figure 1). Internet-based surveys are sent to all participants at baseline, at gestational week 32 , and postpartum at 6 weeks, 6 months and 12 months. Biological samples are collected at several of these points and at childbirth. Furthermore, perinatal health information, especially regarding childbirth, is gathered continuously through linkage to medical journals. The study protocol has been updated several times during its 9-year course (see Data collection section). In every survey, a link enclosed at the end guides participants to the study website and patient information on PND. Women reporting severe signs of depression, for example, suicidal ideation, receive an email asking if they would prefer the researchers to contact them via telephone. Women that prefer a contact receive a call by a member of the research team and are offered practical advice and referral to a psychologist or psychiatrist if appropriate.

Women not answering to follow-up surveys are sent three email reminders. A flowchart of the BASIC participants is presented in figure 2. The follow-up rate is $83.7 \%$ at 6 weeks postpartum, $77.7 \%$ at 6 months postpartum and $70.8 \%$ at the last follow-up at 12 months. Non-responders to the surveys (including dropouts and those skipping a certain survey) are more likely to be multiparous, born outside Scandinavia, have less than 12 years of education, have higher average body mass index (BMI), report a history of depression and report depressive symptoms at baseline, as compared with responders (online supplementary table 1).

This research project was constructed without patient involvement. Patients were not invited to comment on the study design and were not consulted to develop patient relevant outcomes or interpret the results. Patients were not invited to contribute to the writing or editing of this document for readability or accuracy.

\section{Data collection}

An overview of the surveys and biological samples is presented in figure 1. Surveys involve several psychometric self-report instruments (available at the item level) together with questions designed by the research team (table 2). Participants repeatedly answer the Edinburgh Postnatal Depression Scale (EPDS) ${ }^{9}$ and/or the Depression Self-Rating Scale (DSRS) ${ }^{10}$ on depressive symptoms. Anxiety symptoms are measured with the State-Trait Anxiety Inventory for Adults (STAI-AD, state and/or trait scale $)^{11}$ or the Beck Anxiety Inventory (BAI) ${ }^{12}{ }^{13}$ Updates regarding questionnaires over the 9 -year course of the study are outlined in figure 3 . The surveys moreover encompass, for example, obstetrics/ gynaecology information, medical information, lifestyle, sleep, psychological measures (e.g., personality and adult 
Table 1 Sociodemographic information on BASIC study participants and pregnant women in the general population of Uppsala County and Sweden

\begin{tabular}{|c|c|c|c|c|}
\hline Variables & $\begin{array}{l}\text { BASIC pregnancies }{ }^{\star} \dagger \\
2009-2018 \\
(n=6478), n(\%)\end{array}$ & Missing, $\mathbf{n}$ & $\begin{array}{l}\text { Uppsala County } \\
2009-2016 \\
(n=32258), \%\end{array}$ & $\begin{array}{l}\text { Sweden } ¥ \\
2009-2016 \\
(n=902698), \%\end{array}$ \\
\hline Maternal age, years (mean, SD) & $31.5 \pm 4.5$ & 129 & $30.4 \pm 5.2$ & $30.3 \pm 5.3$ \\
\hline Primiparous & 2644 (46.3) & 768 & 44.0 & 44.1 \\
\hline Country of origin & & 969 & & \\
\hline Outside Europe & $191(3.1)$ & & 16.6 & 19.9 \\
\hline Cohabiting with the child's father & $5145(98.4) \S$ & 1250 & 95.7 & 93.1 \\
\hline Education $\leq 12$ years & $1292(23.4)$ & 965 & 46.7 & 48.5 \\
\hline BMI before pregnancy, $\mathrm{kg} / \mathrm{m}^{2}$ & $23.9 \pm 4.2$ & 983 & 24.8 & 24.9 \\
\hline Premature delivery & $268(4.7)$ & 762 & 7.5 & 5.9 \\
\hline
\end{tabular}

Percentages given in relation to available information. Differences between BASIC and Uppsala County, and between BASIC and Sweden, are statistically significant $(p<0.05)$ except for BMI, which could not be statistically tested because of unknown SD for Uppsala County and Sweden. $\chi^{2}$ test for categorical variables and t-test for age with simulated datasets assuming normal distributions.

*Most variables are based on data until 15 November 2018.

†Variables from medical records updated July 2018.

‡Information on Uppsala County and Sweden retrieved from the Swedish Medical Birth Register, hosted by the Swedish National Board of Health and Welfare. Age at childbirth, origin of birth and educational level retrieved from the Education Register and the Register of the Total Population 2009-2014, hosted by Statistics Sweden.

§In BASIC, this question was asked at 6 weeks postpartum.

BASIC, Biology, Affect, Stress, Imaging and Cognition; BMI, body mass index.

attachment), trauma and stressful events, and other questions (e.g., sociodemographic information, partner support and breastfeeding). For detailed information on survey contents beyond psychometric instruments, please see online supplementary table 2 .

The BASIC project contains various modalities of biological sampling (table 3). The main cohort leaves peripheral blood samples at gestational week 16-18 (as part of the Uppsala Biobank for Pregnant Women) and at childbirth. Umbilical cord blood and biopsy are collected at childbirth, for genetic and epigenetic analyses. For a period (2010-2013), childbirth biological samples additionally included placental biopsy and amniotic fluid, in order to investigate possible transcriptional, translational or genetic correlates of PND. Women giving birth with elective CS further contribute with cerebrospinal fluid (CSF), for future analyses that are considered valuable in psychiatric research. Moreover, since 2016, participants leave microbiota samples at multiple times during the study period.

Participants in the study consent to a review of their medical records. The collected information includes, for example, sociodemographic information (overlapping with survey questions), medical history within obstetrics/gynaecology, current medication, pregnancy complications, biochemical analyses (e.g., haemoglobin, thyroid-stimulating hormone), childbirth characteristics (e.g., mode of delivery, induction, analgesia, blood loss and perineal lacerations) and neonatal information (e.g., birth weight and Apgar scores).

\section{Nested case-control group}

A subgroup of the participants are invited to a psychophysiological test session at our research laboratory around gestational week 38 and/or around postpartum week 8 . Invitations to women scoring 12 or more on the EPDS in gestational week 32 or at 6 weeks postpartum are given priority in order to oversample cases with ongoing depression. During pregnancy, we have also prioritised those reporting antidepressant treatment. Twelve points or more is the validated Swedish EPDS cut-off for postpartum depression screening. ${ }^{14}$ Regarding antenatal depression, in 2011 a Swedish validation study recommended a cut-off of 13 points or more ${ }^{15}$; however, we retained the same invitation criteria for consistency. Women scoring $0-11$ on the EPDS are invited as controls and strong priority is given to those with scores between 2 and 6 in order to try to ensure mental well-being among controls.

Between January 2010 and December 2018, 715 and 713 invitations were sent out for pregnancy and postpartum test sessions, respectively. This has resulted in 


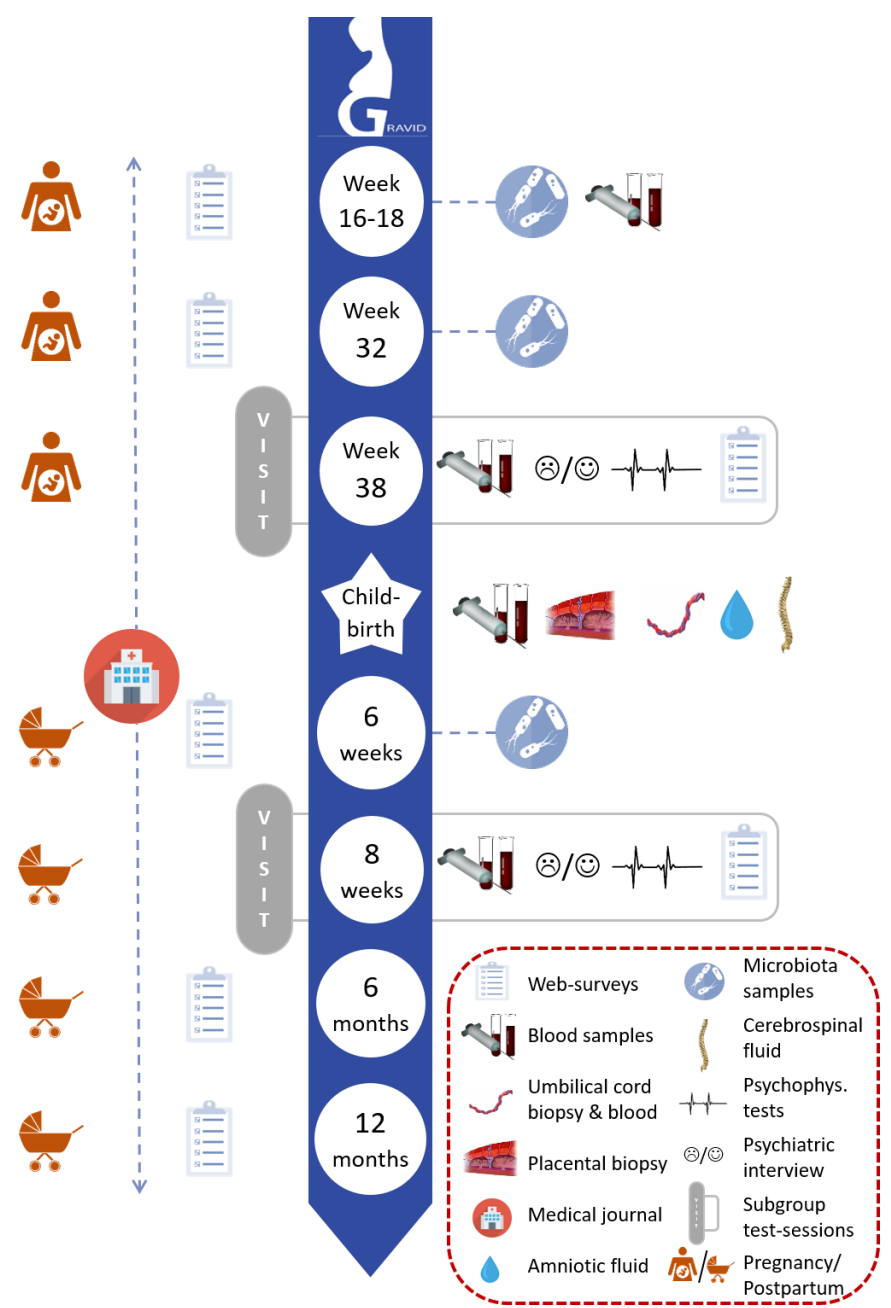

Figure 1 Biology, Affect, Stress, Imaging, and Cognition (BASIC) study timeline and broad categories of measurement. Note: Survey at delivery for a subgroup of women giving birth via elective caesarean section are not shown.

349 (48.8 \% participation rate) pregnancy test sessions and 413 (57.8\% participation rate) postpartum test sessions, including 65 women who have attended at both time points. Of the women invited to the pregnancy test sessions, $36.2 \%$ had screened positive on the EPDS in the previous survey, at gestational week 32 , while $17.8 \%$ had EPDS scores of 7-11, and $46.0 \%$ had scores of $0-6$. Moreover, $8.5 \%$ of test-session participants reported antidepressant treatment, $37.9 \%$ of whom screened positive on the EPDS in the previous survey. At the time of the pregnancy test session, $15.9 \%$ of all women had positive EPDS screening, and according to a structured psychiatric interview (the MINI International Neuropsychiatric Interview), ${ }^{16}{ }^{17} 6.9 \%$ had ongoing major depression. Of those invited to the postpartum test sessions, $37.8 \%$ had left a positive EPDS screening in the previous survey, at 6 weeks postpartum, whereas $8.4 \%$ had scores of $7-11$, and $53.7 \%$ had scores of $0-6$. At the time of the postpartum test session, $23.8 \%$ screened positive on the EPDS and $8.3 \%$ had ongoing major depression according to the MINI. Since 2015, healthy non-pregnant,

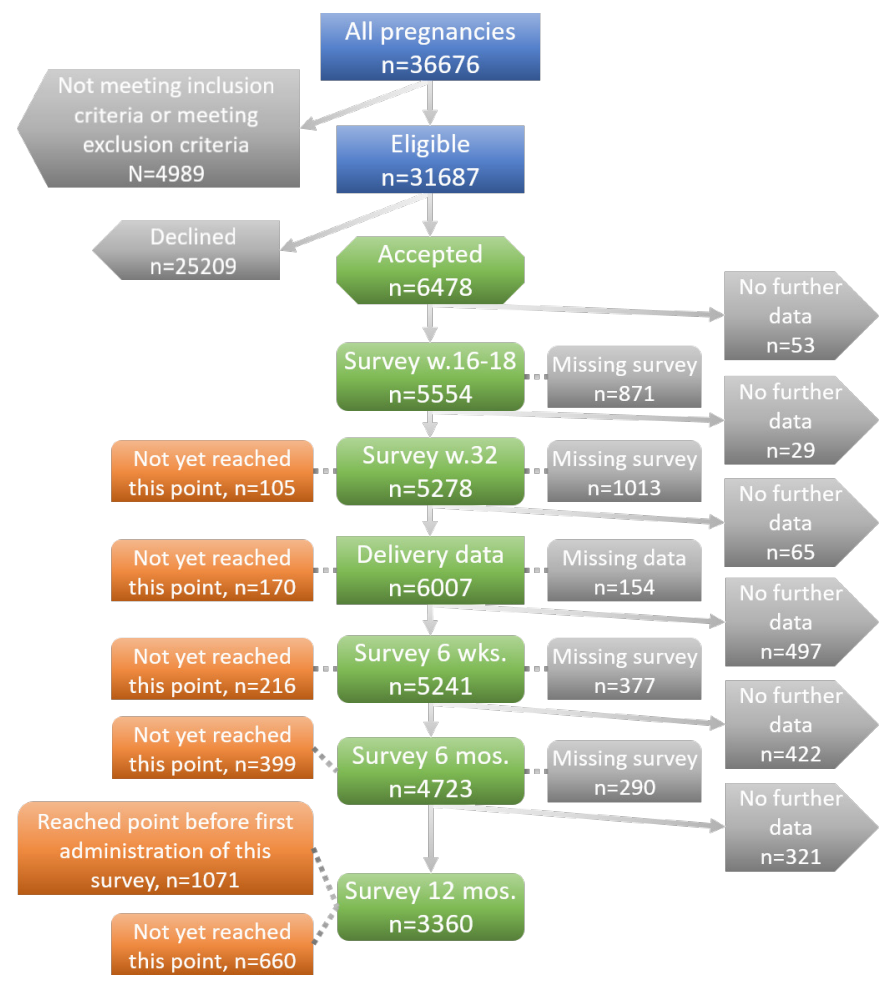

Figure 2 Flowchart of Biology, Affect, Stress, Imaging and Cognition (BASIC) study participants.

non-postpartum women have been invited to the same test-session protocol as described below (not included in study participation flowchart, figure 2). As of 2019, we have recruited 93 participants and the goal is to recruit 200.

During test sessions, women answer self-report instruments on depressive and anxiety symptoms and take part in the MINI International Neuropsychiatric Interview and a test of short-term memory (digit span test). ${ }^{18}$ Furthermore, two sets of complementary cognitive and physiological analyses have been employed during the study course. The first set, implemented in 2010-2014, included measures of sensorimotor gating (prepulse inhibition, PPI) ${ }^{19}$ and attentional bias (emotional Stroop task). ${ }^{20}$ These measures were chosen as we had indications that disrupted PPI would be a sensitive measure for ovarian hormone-related mood disorders ${ }^{21} 22$ and since attentional bias represents a central cognitive alteration associated with depressive episodes. ${ }^{23}$ The second set, implemented after 2014, comprises measures on autonomic nervous system activity (heart rate variability) and body composition (bioimpedance; only postpartum) in order to assess possible correlations with depression which have been increasingly suggested by emerging literature during this period. ${ }^{24} 25$ The number of women engaging in the different modules is presented in table 4 . In addition, the subgroup contributes with samples of peripheral blood, urine and saliva (table 3) in order to enable the assessment of possible correlates in these more easily accessible biological fluids. 
Table 2 Contents of baseline and follow-up surveys

\begin{tabular}{|c|c|c|c|c|c|}
\hline & $\begin{array}{l}\text { Gestational week } \\
\text { 16-18 (baseline) }\end{array}$ & $\begin{array}{l}\text { Gestational } \\
\text { week } 32\end{array}$ & $\begin{array}{l}\text { Postpartum } \\
6 \text { weeks }\end{array}$ & $\begin{array}{l}\text { Postpartum } \\
6 \text { months }\end{array}$ & $\begin{array}{l}\text { Postpartum } 12 \\
\text { months (2013-) }\end{array}$ \\
\hline $\begin{array}{l}\text { Depressive } \\
\text { symptoms }\end{array}$ & $\begin{array}{l}\text { EPDS }^{9} \\
\text { DSRS }^{10}\end{array}$ & EPDS & $\begin{array}{l}\text { EPDS } \\
\text { DSRS (2011-) }\end{array}$ & $\begin{array}{l}\text { EPDS } \\
\text { DSRS (-2011) }\end{array}$ & \\
\hline Anxiety symptoms & $\begin{array}{l}\text { STAI-S } \\
\text { BAI }^{11}(2011-2012) \\
12013-)\end{array}$ & $\begin{array}{l}\text { STAI-S (2011- } \\
2012) \\
\text { STAI-T }{ }^{11}(2011- \\
2012) \\
\text { BAI (2013-) }\end{array}$ & $\begin{array}{l}\text { STAI-S (2011- } \\
\text { 2012) } \\
\text { BAI (2013-) }\end{array}$ & $\begin{array}{l}\text { STAI-S (2011- } \\
\text { 2012) } \\
\text { STAI-T (2011- } \\
2012) \\
\text { BAI (2013-) }\end{array}$ & \\
\hline $\begin{array}{l}\text { Obstetric and } \\
\text { gynaecological } \\
\text { information }\end{array}$ & $\begin{array}{l}\text { Planning of pregnancy* } \\
\text { Nausea/vomiting* } \\
\text { Premenstrual } \\
\text { symptoms* }\end{array}$ & $\begin{array}{l}\text { Pregnancy } \\
\text { complications* } \\
\text { Fear of delivery* } \\
\text { Delivery } \\
\text { expectations }\end{array}$ & $\begin{array}{l}\text { Delivery } \\
\text { information* } \\
\text { Delivery } \\
\text { experience* }\end{array}$ & & \\
\hline Lifestyle & $\begin{array}{l}\text { BMI before pregnancy } \\
\text { Smoking }^{\star}\end{array}$ & $\begin{array}{l}\text { Training, fruit } \\
\text { intake* (2013-) } \\
\text { BMI }\end{array}$ & $\begin{array}{l}\text { Smoking* } \\
\text { Alcohol }^{*}\end{array}$ & $\begin{array}{l}\text { Smoking* } \\
\text { Alcohol }^{*}\end{array}$ & \\
\hline Sleep & $\begin{array}{l}\text { Hours of sleep* } \\
\text { Sleep* }^{*}(2018-)\end{array}$ & $\begin{array}{l}\text { Sleeping problems* } \\
\text { RLS }^{59} \\
\left.\text { Sleep* }^{*} 2018-\right)\end{array}$ & $\begin{array}{l}\text { Sleep quality* } \\
\text { Infant sleep** } \\
(2018-)\end{array}$ & $\begin{array}{l}\text { Sleep quality* } \\
\text { Infant sleep } \\
(2018-)\end{array}$ & $\begin{array}{l}\text { Hours of sleep* } \\
\text { Infant sleep }(2018-\end{array}$ \\
\hline Other & $\begin{array}{l}\text { Sociodemographic } \\
\text { information: age, } \\
\text { marital status, country } \\
\text { of birth, education, } \\
\text { employment* }^{*}\end{array}$ & & $\begin{array}{l}\text { Partner support* } \\
\text { Breastfeeding } \\
\text { General questions, } \\
\text { life right now* }\end{array}$ & $\begin{array}{l}\text { Partner support* } \\
\text { Breastfeeding } \\
\text { General questions, } \\
\text { life right now* }\end{array}$ & $\begin{array}{l}\text { Breastfeeding }{ }^{\star} \\
\text { (2013-) } \\
\text { General questions, } \\
\text { life right now* } \\
\text { (2013-) }\end{array}$ \\
\hline
\end{tabular}

Period of usage is stated in parentheses if other than 2009-2017.

${ }^{*}$ Questions designed by the research team.

ASQ, Attachment Style Questionnaire; BAI, Beck Anxiety Inventory; DSRS, Depression Self-Rating Scale; EPDS, Edinburgh Postnatal Depression Scale; IBQ, Infant Behavioral Questionnaire; LITE, Lifetime Incidence of Traumatic Events; PBQ, Postpartum Bonding Questionnaire; RLS, Restless legs questionnaire; RS-14, Resilience Scale; SLES, Stressful Life Events Scale; SOC-29, Sense of Coherence; SQ-PTSD, Screen Questionnaire-Post-Traumatic Stress Disorder; SSP, Swedish universities Scales of Personality; STAI-S, State-Trait Anxiety Inventory-State scale; STAI-T, State-Trait Anxiety Inventory-Trait scale; VPSQ, Vulnerable Personality Style Questionnaire.

\section{Elective caesarean subgroup}

Since 2013, a separate track of recruitment has invited women scheduled for an elective CS, who are not already part of the study. As a substitution to the pregnancy surveys of the main cohort, these women answer a survey around the time of childbirth with retrospective information regarding their pregnancy together with current symptomatology (e.g., the EPDS). From childbirth and onwards, they are followed-up according to the usual study protocol including biological samples and surveys. Characteristic of this subgroup is the contribution of CSF samples at childbirth, which they have in common with women delivering via elective $\mathrm{CS}$ in the main recruitment track (table 3 ).

\section{Cortisol subgroups}

Between December 2011 and March 2012, as well as between June and August 2012, 365 women from the 


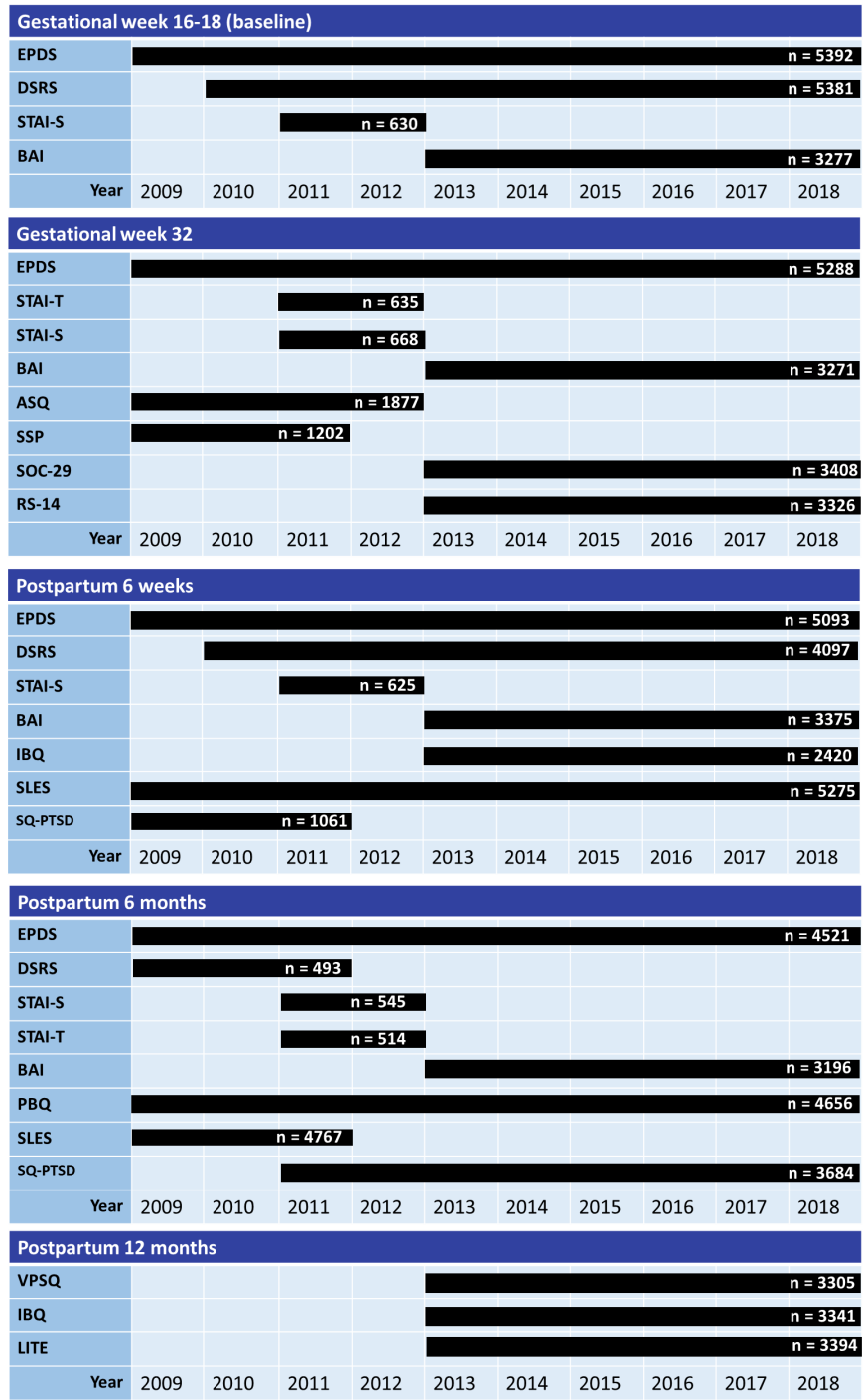

Figure 3 Periods of usage and number of respondents of psychometric questionnaires in the surveys. ASQ, Attachment Style Questionnaire ${ }^{48}$; BAI, Beck Anxiety Inventory ${ }^{12}{ }^{13}$; DSRS, Depression Self-Rating Scale ${ }^{10}$; EPDS, Edinburgh Postnatal Depression Scale ${ }^{9}$; IBQ, Infant Behavioural Questionnaire ${ }^{49}$; LITE, Lifetime Incidence of Traumatic Events ${ }^{50}$; PBQ,

Postpartum Bonding Questionnaire ${ }^{51}$ 52; RS-14, Resilience Scale $^{53}$; SOC-29, Sense of Coherence ${ }^{54}$; SQ-PTSD, Screen Questionnaire-Post-Traumatic Stress Disorde ${ }^{55}$; STAI-S, State-Trait anxiety Inventory-State scale ${ }^{11}$; STAI-T, State-Trait Anxiety Inventory-Trait scale ${ }^{11}$; SLES, Stressful Life Events Scale ${ }^{56}$; SSP, Swedish universities Scales of Personality ${ }^{57}$; VPSQ, Vulnerable Personality Style Questionnaire. ${ }^{58}$

main cohort were invited to enrol in the evening cortisol subgroup at gestational week 36. Study participants received written instructions to provide self-collected evening salivary cortisol samples (between 20:00 and 22:00), collected at home by use of a kit sent by post, at gestational week 36 and at 6 weeks postpartum. At the same points, the EPDS questionnaire was answered. Collection of saliva is an easy, non-invasive process that can be performed in home settings. Salivary cortisol is a measure of the free cortisol level and cortisol is active only in the unbound state. This is beneficial especially in pregnant subjects as altered concentrations of corticosteroid-binding globulin may complicate the interpretation of total plasma cortisol during pregnancy. Moreover, the chosen method facilitates comparison with previous studies (please see Iliadis $e t a l^{26}$ for literature review). The time frame was chosen to facilitate participation, taking into consideration the unique and demanding circumstances of the early postpartum period. Moreover, the fluctuations of cortisol levels during this interval were expected to be small. Initially, 284 women (78\%) at gestational week 36 and $243(67 \%)$ at 6 weeks postpartum agreed to participate by providing salivary samples. Valid cortisol samples along with a completed EPDS questionnaire were collected from 268 women at gestational week $36(94 \%)$ and 181 women postpartum $(79 \%)$, who constitute the final evening cortisol subgroup.

Additionally, between 2010 and 2012, another subgroup of women $(n=216)$ were invited to contribute with self-collected morning salivary cortisol samples in gestational week 38. Women were instructed to collect samples immediately after awakening, and at 15, 30 and 45 min postawakening, to enable studies on the cortisol awakening response. A total of 161 women completed the morning sampling. The evening and morning samples were requested from different groups of women in order to avoid low compliance.

\section{Findings to date}

Up to this point, publications based on the BASIC cohort ( www.basicstudie.se/publicerade-arbeten) have described various risk factors for PND (figure 4). In a recent article, we outline correlates to different symptomatic trajectories across our broad set of measurements. ${ }^{27}$

Several findings concern dysregulation of the hypothalamic-pituitary-adrenal (HPA) axis. High corticotropin-releasing hormone $(\mathrm{CRH})$ levels in midpregnancy were found to be associated with the use of antidepressants, ${ }^{28}$ but cortisol awakening response did not differ between pregnant women with or without depressive symptoms. ${ }^{29}$ However, postpartum cortisol levels were associated with concurrent depressive symptoms ${ }^{26}$ and $\mathrm{CRH}$ levels of non-depressed pregnant women in gestational week 17 were higher among those who developed de novo depressive symptoms postpartum, compared with healthy controls. ${ }^{30}$ These results indicate a dysregulation of the HPA axis, several weeks prior to the occurrence of postpartum depressive symptoms, and are consistent with the hypothesis that, after delivery, the HPA axis of depressed women may be temporarily suppressed because of an effect of high circulating levels of CRH during pregnancy on adrenal function. This may result in greater residual hypothalamic suppression and HPA-axis hypoactivity in the postpartum period, which could predispose vulnerable individuals for depression with postpartum onset. Moreover, a single nucleotide polymorphism of a gene implicated in the cortisol metabolism, the hydroxysteroid (11-beta) dehydrogenase 1 (HSD11B1), is associated with both the personality domain of neuroticism and 


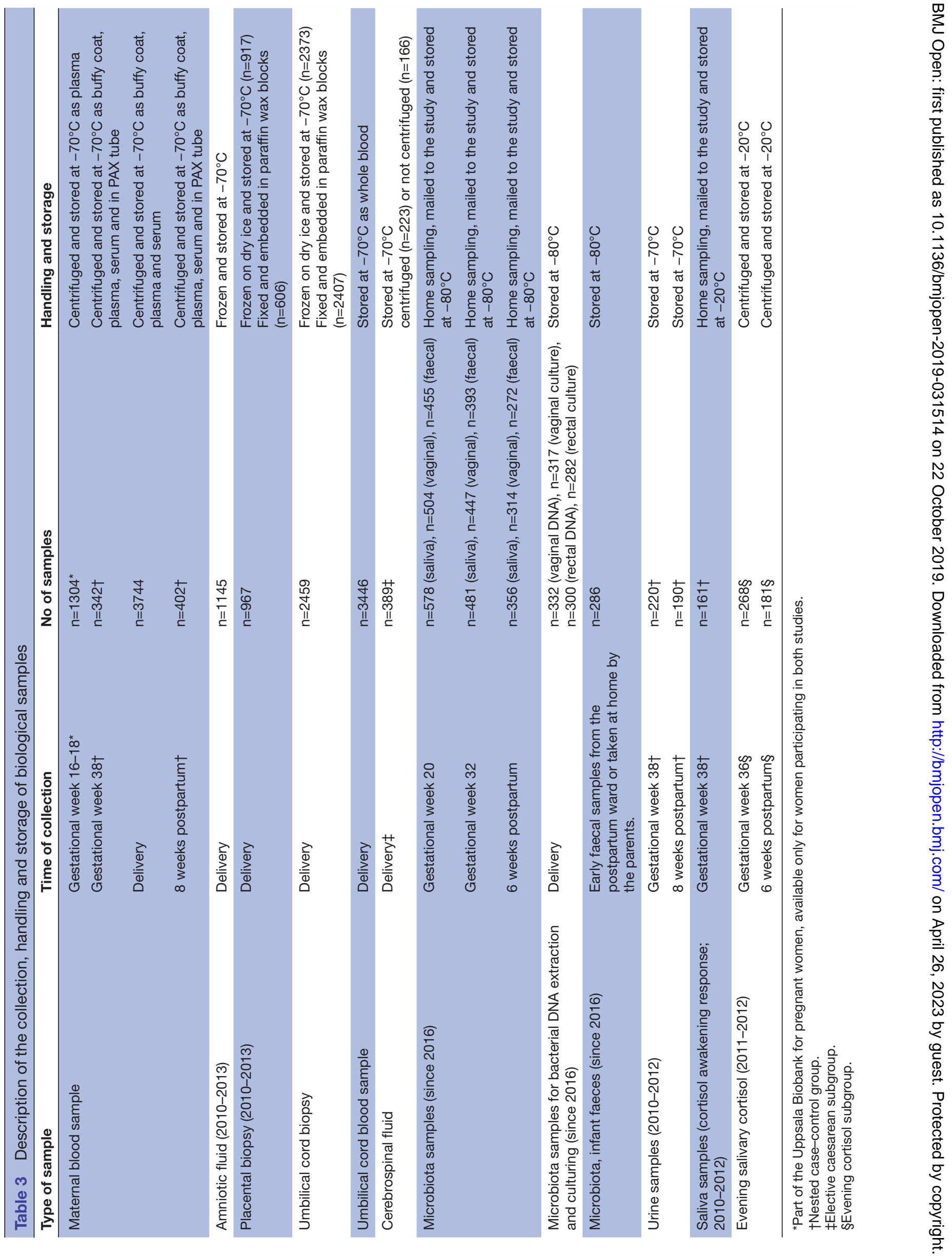


Table 4 Test-session modules for the nested case-control group

\begin{tabular}{|c|c|c|}
\hline Measure & $\begin{array}{l}\text { Pregnancy test session } \\
\text { (gestational week } 38 \text { ) } n=349\end{array}$ & $\begin{array}{l}\text { Postpartum test session (postpartum } \\
\text { week 8), } n=413\end{array}$ \\
\hline \multirow[t]{2}{*}{ Self-report questionnaires } & $\begin{array}{l}\text { EPDS, MADRS, }{ }^{60} \text { STAI-S, STAI-T, } \\
\text { IUS, }{ }^{61} \mathrm{n}=349\end{array}$ & $\begin{array}{l}\text { EPDS, MADRS, STAI-S, STAI-T, IUS, } \\
n=413\end{array}$ \\
\hline & MUS, $^{62} \mathrm{n}=112$ & MUS, $n=205$ \\
\hline $\begin{array}{l}\text { MINI International Neuropsychiatric Interview, } \\
\text { Module } A^{*}\end{array}$ & $\mathrm{n}=346$ & $\mathrm{n}=394$ \\
\hline \multirow[t]{3}{*}{ Psychophysiological measurements } & PPI, $n=217$ & PPI, $n=170$ \\
\hline & $H R V, n=109$ & $H R V, n=178$ \\
\hline & & Bioimpedance, $n=187$ \\
\hline \multirow[t]{2}{*}{ Cognitive tests } & Digit span test, $n=344$ & Digit span test, $\mathrm{n}=337$ \\
\hline & Emotional Stroop task, $\mathrm{n}=201$ & Emotional Stroop task, $n=171$ \\
\hline
\end{tabular}

*Depressive episodes (Swedish version). Over the years, additional modules have been used.

EPDS, Edinburgh Postnatal Depression Scale; HRV, heart rate variability; IUS, Intolerance of Uncertainty Scale; MADRS-S, MontgomeryÅsberg Depression Rating Scale; MUS, medically unexplained symptoms; PPI, prepulse inhibition; STAI-S and STAI-T, State Trait Anxiety Inventory.

postpartum depressive symptoms. ${ }^{31}{ }^{32}$ Neuroticism ${ }^{33}$ and attachment anxiety ${ }^{34}$ have been identified as important, and not entirely overlapping, predisposing psychological factors for postpartum depressive symptoms. These adjusted associations in a prospective material provide support for a model of personality as a vulnerability factor for PND and suggest benefits of combining perspectives from the largely separated fields of hormonal stress responses, personality and attachment in the study of PND aetiology.

The role of the immune system in PND has been explored in studies on inflammatory markers. Women with antenatal depression or on Selective Serotonin Reuptake Inhibitor (SSRI) treatment during pregnancy had lower levels in 23 inflammatory markers in comparison to healthy pregnant controls. ${ }^{35}$ Several of the top-down regulated markers, such as TNF-relatedapoptosis-inducing ligand (TRAIL), Macrophagecolony-stimulating factor 1 (CSF-1), Fractalkine (CX3CL1), Vascular endothelialgrowth factor A (VEGF-A) and Interleukin-15receptor subunit alpha (IL15R $\alpha$ ), have been associated with M2 macrophage function. When studying pregnant women that later presented with postpartum depressive symptoms, there was no support for the use

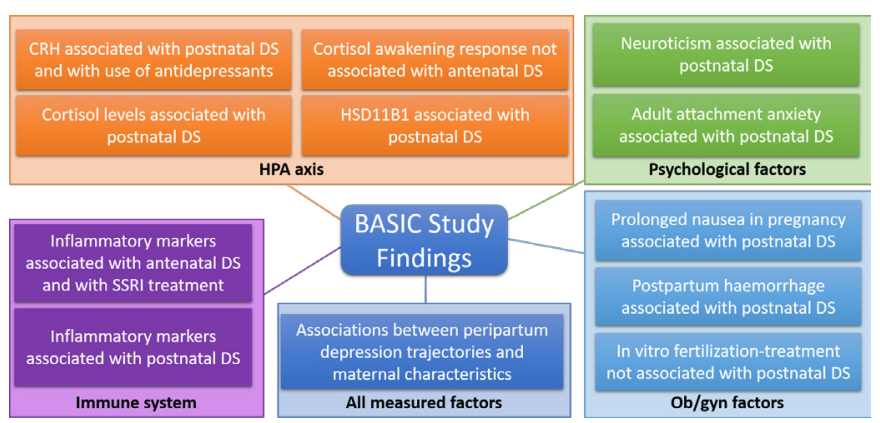

Figure 4 Areas of Biology, Affect, Stress, Imaging and Cognition (BASIC) study findings with examples. of any inflammatory marker by itself in late pregnancy for predicting the risk of depression development. ${ }^{36}$ However, Signal transducing adaptor molecule-binding protein (STAM-BP) might be useful in combination with other biological markers in the future. When comparing women with depressive symptoms postpartum with healthy postpartum controls, five of the markers (TNF-related activation-induced cytokine (TRANCE), Hepatocyte growthfactor (HGF), Interleukin (IL)-18, Fibroblast growth factor (FGF)-23 and Chemokine (c-X-C motif) ligand 1 (CXCL1)) were elevated in affected women. ${ }^{37}$ When comparing pregnant and postpartum euthymic women, 41 markers had decreasing levels and 9 markers increased in the postpartum period. ${ }^{38}$ The three markers that decreased most from pregnancy to postpartum were Leukemiainhibitory factor receptor (LIF-R), Latency-associated peptide transforming growth factor beta-1 (LAP TGFbeta1) and C-C motif chemokine 28 (CCL28), while the three markers increasing the most were TRANCE, Tumor necrosis factorligand superfamily member 12 (TWEAK) and Eotaxin (CCL11). In summary, no marker in any of the studies investigating PND was distinct enough to be used as a sole diagnostic tool. However, findings underline the plasticity of the immune system during this period and further research on its role in PND is warranted.

Obstetric factors have also been investigated. Prolonged nausea during pregnancy is associated with the development of depressive symptoms postpartum. ${ }^{39}$ An association between heavy postpartum haemorrhage and postpartum depressive symptoms was found to be mediated by postpartum anaemia. ${ }^{40}$ Mode of delivery was not directly associated with postpartum depressive symptoms; however, emergency CS or vacuum extraction was a factor associated with higher risk. ${ }^{41}$ Moreover, conception by means of in vitro fertilisation was not a risk factor for antenatal or postpartum depressive symptoms. ${ }^{42}$ 
In addition to PND, the BASIC project has incorporated placental and fetal outcomes. For example, young maternal age and excessive maternal weight gain are associated with a higher prenatal androgen exposure of female fetuses. ${ }^{43}$ Antenatal depression and antidepressant exposure during pregnancy were associated with an altered gene expression in the placenta. ${ }^{44}$ Another study showed that the elevated risk of preterm birth in antidepressant (SSRI) users was not mediated by increased placental CRH production. ${ }^{28}$ In women with psychiatric morbidity, maternal cortisone to cortisol ratio was positively associated with birth weight, also after adjustment for several potential confounders. ${ }^{45}$

Since the lion's share of this data collection is yet to be analysed, future plans on the BASIC study material involve many potential subprojects. For example, machine learning methods applied to the multimodal measurements of the BASIC study are now implemented, with analyses ongoing.

\section{Strengths and limitations}

As a population-based, longitudinal study with several follow-up points, the BASIC study has a richness in data on an individual level comprising a biopsychosocial context. Thus, it enables a great level of detail in epidemiological investigations. Furthermore, its sample size is one of the largest in the field.

The relatively low acceptance rate may raise doubts about the cohort's representability. Baseline comparison with the general population indicates that participants have a sociodemographic low-risk profile. A possible contributing factor is the enrolment in a university town. However, regarding the acceptance rate as such, the BASIC study may not differ substantially from other longitudinal studies in the perinatal period. Moreover, it must be noted that the sample has a relatively low rate of depressive symptoms. Among participants, there was a greater dropout among women with baseline depressive symptoms. Still, rates of clinically relevant depressive symptoms correspond to earlier reports ${ }^{46}$ across the whole follow-up, perhaps since loss to follow-up was relatively limited. Under-representation at baseline and higher attrition of women at risk are common challenges for prospective studies of peripartum mental health ${ }^{47}$. Whereas this project's approach has been ambitiously broad, future cohort studies might want to prioritise among measures in order to facilitate participation. The acceptability of consecutive surveys might be addressed by employing validated short versions of questionnaires, or by using technical tools that enable a convenient distribution of batches of questions (eg, smartphone applications). Furthermore, researchers may consider developing multilingual study instructions and consult experts of how to adapt question formatting for minority groups.

Largely, symptoms of depression and anxiety were assessed by self-report surveys, which may introduce certain types of information bias. On the other hand, the majority of questions belonged to instruments that are psychometrically evaluated and widely accepted in the field, for example, the EPDS. ${ }^{9}$ For nearly all participants, the DSRS, which is based on the Diagnostic and Statistical Manual of Mental Disorders (DSM)-IV depression criteria, is available both during pregnancy and after delivery. Furthermore, the MINI International Psychiatric Interview is also available for a subset of the cohort.

\section{Collaboration}

Researchers interested in collaboration may contact Professor Alkistis Skalkidou (corresponding author) with their request. The BASIC study steering committee considers the scientific quality of the aims and methods of incoming requests in addition to the volume of the requested data or samples. The committee prioritises study questions on PND.

Acknowledgements The authors wish to profoundly thank and acknowledge Marianne Kördel, Ingegerd Clason, Lena Moby, Lisa Wernroth, Anastasia Kollia, Linn Wallen, Elin Bannbers, Anna-Karin Hannefors, Elisabeth Hansson and all the participating women.

Contributors AS conceived of and designed the study together with FCP, SS, ISP and LE. Data acquisition, analysis and interpretation were carried out by $A S, C A, E B$, $\mathrm{HEH}, \mathrm{CH}, \mathrm{TKK}, \mathrm{EF}, \mathrm{SL}, \mathrm{SIl}$ and SS. After CA drafted the article, all authors revised it and approved the final version.

Funding This work was supported by the Swedish Research Council (Grant numbers 523-2014-2342, 523-2014-07605 and 521-2013-2339); the Uppsala University Hospital; the Göran Gustafsson Foundation; the Swedish Brain Foundation; Marianne and Marcus Wallenberg Foundation; the Söderström Königska Foundation; the Swedish Society of Medicine; the Crime Victim Compensation and Support Authority; the P.0. Zetterling Foundation; the Swedish Council for Working Life and Social Research; the Family Planning Foundation; the Fredrik and Ingrid Thuring Foundation; the Födelsefonden; The General Maternity Hospital Foundation; the Gillbergska Foundation; the Märta and Nicke Nasvell Foundation; the Professor Bror Gadelius Memorial Fund; and the Naeslund Scholarship.

Competing interests None declared.

Patient consent for publication Not required.

Ethics approval The study has been approved by the Regional Ethical Review Board in Uppsala (Reference number 2009/171) with amendments covering, for example, collection of microbiota samples, inclusion of healthy non-pregnant women and genome-wide association analysis. A separate application has been approved regarding the linkage to Swedish national health registers (Reference number 2017/276).

Provenance and peer review Not commissioned; externally peer reviewed.

Data availability statement Data are available on reasonable request.

Open access This is an open access article distributed in accordance with the Creative Commons Attribution Non Commercial (CC BY-NC 4.0) license, which permits others to distribute, remix, adapt, build upon this work non-commercially, and license their derivative works on different terms, provided the original work is properly cited, appropriate credit is given, any changes made indicated, and the use is non-commercial. See: http://creativecommons.org/licenses/by-nc/4.0/.

\section{ORCID iDs}

Cathrine Axfors http://orcid.org/0000-0002-2706-1730

Emma Bränn http://orcid.org/0000-0001-9664-7973

Emma Fransson http://orcid.org/0000-0001-9010-8522

Susanne Lager http://orcid.org/0000-0003-3556-065X

Alkistis Skalkidou http://orcid.org/0000-0002-4935-7532

\section{REFERENCES}

1 Woody CA, Ferrari AJ, Siskind DJ, et al. A systematic review and meta-regression of the prevalence and incidence of perinatal depression. J Affect Disord 2017;219:86-92.

2 Howard LM, Molyneaux E, Dennis C-L, et al. Non-psychotic mental disorders in the perinatal period. The Lancet 2014;384:1775-88. 
3 Lovejoy MC, Graczyk PA, O'Hare E, et al. Maternal depression and parenting behavior: a meta-analytic review. Clin Psychol Rev 2000;20:561-92.

4 Field T. Postpartum depression effects on early interactions, parenting, and safety practices: a review. Infant Behav Dev 2010;33:1-6.

5 Kingston D, Tough S, Whitfield H. Prenatal and postpartum maternal psychological distress and infant development: a systematic review. Child Psychiatry Hum Dev 2012;43:683-714.

6 Josefsson A, Sydsjö G. A follow-up study of postpartum depressed women: recurrent maternal depressive symptoms and child behavior after four years. Arch Womens Ment Health 2007;10:141-5.

7 Esscher A, Essén B, Innala E, et al. Suicides during pregnancy and 1 year postpartum in Sweden, 1980-2007. Br J Psychiatry 2016;208:462-9.

8 Yim IS, Tanner Stapleton LR, Guardino CM, et al. Biological and psychosocial predictors of postpartum depression: systematic review and call for integration. Annu Rev Clin Psychol 2015;11:99-137.

9 Cox JL, Holden JM, Sagovsky R. Detection of postnatal depression. development of the 10-item Edinburgh postnatal depression scale. Br J Psychiatry 1987;150:782-6.

10 Zung WW. A self-rating depression scale. Arch Gen Psychiatry 1965:12:63-70.

11 Spielberger CD, Gorsuch RL, Lushene R, et al. Manual for the State-Trait anxiety inventory. Palo Alto, CA: Consulting Psychologists Press, 1983.

12 Beck AT, Epstein N, Brown G, et al. An inventory for measuring clinical anxiety: psychometric properties. J Consult Clin Psychol 1988;56:893-7.

13 Beck AT, Steer RA, Carbin MG. Psychometric properties of the Beck depression inventory: twenty-five years of evaluation. Clin Psychol Rev 1988;8:77-100.

14 Wickberg B, Hwang CP. The Edinburgh postnatal depression scale: validation on a Swedish community sample. Acta Psychiatr Scand 1996;94:181-4.

15 Rubertsson C, Börjesson K, Berglund A, et al. The Swedish validation of Edinburgh postnatal depression scale (EPDS) during pregnancy. Nord J Psychiatry 2011;65:414-8.

16 Sheehan DV, Lecrubier Y, Sheehan KH, et al. The Mini-International Neuropsychiatric Interview (M.I.N.I.): the development and validation of a structured diagnostic psychiatric interview for DSM-IV and ICD10

17 Allgulander C, Waern M, Humble M, et al. M.I.N.I mini Internationell Neuropsykiatrisk Intervju. Svensk version 6.0.0. Karolinska Institutet, Stockholm och Sahlgrenska akademin, 2009.

18 Wikman A, Axfors C, lliadis Sl, et al. Characteristics of women with different perinatal depression trajectories. J Neurosci Res 2019;6.

19 Wechsler D. WAIS-III. Svensk version. Kristianstad: Psykologiförlaget $a b, 2003$.

20 Comasco E, Gulinello M, Hellgren C, et al. Sleep duration, depression, and oxytocinergic genotype influence prepulse inhibition of the startle reflex in postpartum women. Eur Neuropsychopharmacol 2016;26:767-76.

21 Edvinsson Åsa, Skalkidou A, Hellgren C, et al. Different patterns of attentional bias in antenatal and postpartum depression. Brain Behav 2017;7:e00844.

22 Kask K, Bäckström T, Gulinello M, et al. Lower levels of prepulse inhibition of startle response in pregnant women compared to postpartum women. Psychoneuroendocrinology 2008;33:100-7.

23 Kask K, Gulinello M, Bäckström T, et al. Patients with premenstrual dysphoric disorder have increased startle response across both cycle phases and lower levels of prepulse inhibition during the late luteal phase of the menstrual cycle. Neuropsychopharmacology 2008;33:2283-90.

24 Gotlib IH, Joormann J. Cognition and depression: current status and future directions. Annu Rev Clin Psychol 2010;6:285-312.

$25 \mathrm{Kemp}$ AH, Quintana DS, Quinn CR, et al. Major depressive disorder with melancholia displays robust alterations in resting state heart rate and its variability: implications for future morbidity and mortality. Front Psychol 2014;5:1387.

26 Deuschle M, Gilles M. Hypercortisolemic depressed women: lean but Viscerally obese? Neuroendocrinology 2016;103:263-8.

27 Iliadis SI, Comasco E, Sylvén S, et al. Prenatal and postpartum evening salivary cortisol levels in association with peripartum depressive symptoms. PLoS One 2015;10:e0135471.

28 Hannerfors A-K, Hellgren C, Schijven D, et al. Treatment with serotonin reuptake inhibitors during pregnancy is associated with elevated corticotropin-releasing hormone levels. Psychoneuroendocrinology 2015;58:104-13.
29 Hellgren C, Åkerud H, Skalkidou A, et al. Cortisol awakening response in late pregnancy in women with previous or ongoing depression. Psychoneuroendocrinology 2013;38:3150-4.

30 Iliadis SI, Sylvén S, Hellgren C, et al. Mid-Pregnancy corticotropinreleasing hormone levels in association with postpartum depressive symptoms. Depress Anxiety 2016;33:1023-30.

31 lliadis SI, Comasco E, Hellgren C, et al. Associations between a polymorphism in the hydroxysteroid (11-beta) dehydrogenase 1 gene, neuroticism and postpartum depression. J Affect Disord 2017:207:141-7.

32 Skalkidou A, Poromaa IS, lliadis SI, et al. Stress-Related genetic polymorphisms in association with peripartum depression symptoms and stress hormones: a longitudinal population-based study. Psychoneuroendocrinology 2019;103:296-305.

33 lliadis SI, Koulouris P, Gingnell M, et al. Personality and risk for postpartum depressive symptoms. Arch Womens Ment Health 2015;18:539-46.

34 Axfors C, Sylvén S, Ramklint M, et al. Adult attachment's unique contribution in the prediction of postpartum depressive symptoms, beyond personality traits. J Affect Disord 2017;222:177-84.

35 Edvinsson Åsa, Bränn E, Hellgren C, et al. Lower inflammatory markers in women with antenatal depression brings the M1/M2 balance into focus from a new direction. Psychoneuroendocrinology 2017;80:15-25

36 Bränn E, Papadopoulos F, Fransson E, et al. Inflammatory markers in late pregnancy in association with postpartum depression-A nested case-control study. Psychoneuroendocrinology 2017;79:146-59.

37 Bränn E, Fransson E, White RA, et al. Inflammatory markers in women with postpartum depressive symptoms. J Neurosci Res 2018;11.

38. Bränn E, Edvinsson Å, Rostedt Punga A, et al. Inflammatory and anti-inflammatory markers in plasma: from late pregnancy to early postpartum. Sci Rep 2019;9.

39 lliadis SI, Axfors C, Johansson S, et al. Women with prolonged nausea in pregnancy have increased risk for depressive symptoms postpartum. Sci Rep 2018;8:15796.

40 Eckerdal P, Kollia N, Löfblad J, et al. Delineating the association between heavy postpartum haemorrhage and postpartum depression. PLoS One 2016;11:e0144274.

41 Eckerdal P, Georgakis MK, Kollia N, et al. Delineating the association between mode of delivery and postpartum depression symptoms: a longitudinal study. Acta Obstet Gynecol Scand 2018;97:301-11.

42 Gambadauro P, lliadis S, Bränn E, et al. Conception by means of in vitro fertilization is not associated with maternal depressive symptoms during pregnancy or postpartum. Fertil Steril 2017;108:325-32.

43 Kallak TK, Hellgren C, Skalkidou A, et al. Maternal and female fetal testosterone levels are associated with maternal age and gestational weight gain. Eur J Endocrinol 2017;177:379-88.

44 Olivier JDA, Åkerud H, Sundström Poromaa I. Antenatal depression and antidepressants during pregnancy: unraveling the complex interactions for the offspring. Eur J Pharmacol 2015;753:257-62.

45 Hellgren C, Edvinsson Ảsa, Olivier JD, et al. Tandem mass spectrometry determined maternal cortisone to cortisol ratio and psychiatric morbidity during pregnancy-interaction with birth weight. Psychoneuroendocrinology 2016;69:142-9.

46 Rubertsson C, Wickberg B, Gustavsson P, et al. Depressive symptoms in early pregnancy, two months and one year postpartumprevalence and psychosocial risk factors in a national Swedish sample. Arch Womens Ment Health 2005;8:97-104.

47 van Bussel JCH, Spitz B, Demyttenaere K. Depressive symptomatology in pregnant and postpartum women. An exploratory study of the role of maternal antenatal orientations. Arch Womens Ment Health 2009;12:155-66.

48 Feeney JA, Noller P, Hanrahan M. Assessing adult attachment. In: Sperling MB, Berman WH, eds. Attachment in adults: clinical and developmental perspectives. New York: Guilford Press, 1994: 128-52.

49 Rothbart MK. Measurement of temperament in infancy. Child Dev 1981:52:569-78.

50 Greenwald R, Rubin A. Assessment of posttraumatic symptoms in children: development and preliminary validation of parent and child scales. Res Soc Work Pract 1999;9:61-75.

51 Brockington IF, Oates J, George S, et al. A screening questionnaire for mother-infant bonding disorders. Arch Womens Ment Health 2001;3:133-40.

52 Brockington IF, Fraser C, Wilson D. The postpartum bonding questionnaire: a validation. Arch Womens Ment Health 2006;9:233-42.

53 Wagnild GM, Young HM. Development and psychometric evaluation of the resilience scale. J Nurs Meas 1993:1:165-78. 
54 Antonovsky A. The structure and properties of the sense of coherence scale. Soc Sci Med 1993;36:725-33.

55 Frans O, Rimmö P-A, Aberg L, et al. Trauma exposure and posttraumatic stress disorder in the general population. Acta Psychiatr Scand 2005;111:291-290.

56 Horowitz M, Wilner N, Alvarez W. Impact of event scale: a measure of subjective stress. Psychosom Med 1979;41:209-18.

57 Gustavsson JP, Bergman H, Edman G, et al. Swedish universities scales of personality (ssp): construction, internal consistency and normative data. Acta Psychiatr Scand 2000;102:217-25.

58 Boyce P, Hickey A, Gilchrist J, et al. The development of a brief personality scale to measure vulnerability to postnatal depression. Arch Womens Ment Health 2001:3:147-53.
59 Allen RP, Burchell BJ, MacDonald B, et al. Validation of the selfcompleted Cambridge-Hopkins questionnaire (CH-RLSq) for ascertainment of restless legs syndrome (RLS) in a population survey. Sleep Med 2009;10:1097-100.

60 Montgomery SA, Åsberg M. A new depression scale designed to be sensitive to change. Br J Psychiatry 1979;134:382-9.

61 Carleton RN, Norton MAPJ, Asmundson GJG. Fearing the unknown: a short version of the intolerance of uncertainty scale. J Anxiety Disord 2007;21:105-17.

62 Tsigos C, Stefanaki C, Lambrou Gl, et al. Stress and inflammatory biomarkers and symptoms are associated with bioimpedance measures. Eur J Clin Invest 2015;45:126-34. 